Original Article $\quad$ www.pjkd.com.pk

\title{
Acquiring Hepatitis-C Viral Infection during Maintenance Hemodialysis Patients at DHQ Hospital Sheikhupura: A Cross Sectional Study
}

\author{
Yaris Hussain, Anum Sabir, Saba Naz, Nazish Munawar, Roshina Anjum.
}

Department of Nephrology,

Ameer-u-din Medical College

Postgraduate Medical Institute

Lahore General Hospital.

Lahore, Pakistan

\begin{abstract}
:
Background: End stage kidney disease (ESKD) is one of the end results of chronic kidney disease. In center hemodialysis is the most common renal replacement therapy (RRT) for these patients used in Pakistan. It is associated with increased risk of health care-related infections. Hepatitis-C is the frequent blood born viral infection in hemodialysis center. Its frequency is very high in hemodialysis patients as compared to general and even to thalassemia population.

Purpose of the study: To assess the gravity of Hepatitis-C viral infection in hemodialysis patients.

Methods: A retrospective cross-sectional study done in dialysis center of DHQ hospital Sheikhupura, Punjab, Pakistan in January 2018. All the patients who had started hemodialysis with HCV negative status and had remained on hemodialysis for more than three months were included in the study. Patients with Hepatitis-C positive status, acute kidney disease and on dialysis less than three months were excluded. All patients were tested by enzymes linked immune-sorbent essay (ELISA) method for HCV status.

Results: Out of 153 Hepatitis-C negative patients at the time of initiation of dialysis, 60 (39.21\%) converted positive while 93 (60.78 \%) were still HCV negative by ELISA method at the time of study. Number of dialysis were having significant $\mathrm{p}$ value.

Conclusion: Most of the patients had acquired Hepatitis-C infection during in-center hemodialysis. This emphasizes the importance of stringent infection prevention and control practices.
\end{abstract}

Key words: Hepatitis-C; hemodialysis; nephrologist, reuse, dialyzer, HCV seroconversion, blood transfusion, isolation.

\section{Corresponding Author:}

Dr. Yasir Hussain

Assistant Professor

AMC/PGMI/LGH

Ex-Consultant Nephrologist DHQ hospital Sheikhupura

Email:dryasirhussain.yh@gmail.com

Received: February 20,2020. Accepted April 25,2020.

PJKD 2020(4);2:240-244

\section{Introduction:}

Life cannot be sustained in End stage kidney disease (ESKD) without renal replacement therapy (RRT) including, hemodialysis (HD), peritoneal dialysis (PD) and renal transplant (RT). ${ }^{1}$ Chronic kidney disease (CKD) is one of chronic diseases which have high prevalence (12.5\% -25.6\%) in Pakistani population (Jessani et al., 2014), (Imran et al., 2015). ${ }^{2.3}$ Maintenance hemodialysis is the frequently opted to sustain life on dialysis twice or thrice weekly. Each session of hemodialysis is from three to six hours with four hours session for most of the patients. During each session patient's blood is exposed to extracorporeal circuit. At this time patient are at risk for healthcare-associated infections (HAIs) especially Hepatitis-C and causes huge burden on health, finance and society. ${ }^{4.5}$

Hepatitis-C virus is a member of flaviviride family spreading via blood, blood products and sexual contacts. Risks factors for HAIs are cross-contamination of instruments/medications, inadequate disinfection of dialysis equipment, failure to use proper hand hygiene, failure to adhere to infection prevention and control (IPC) standard practices. ${ }^{6}$ Prevalence of $\mathrm{HCV}$ is $6.8 \%$ in general population in Pakistan, much higher as compared to global prevalence of $2.5 \%$ in general population. ${ }^{7}$ Prevalence in hemodialysis is variable ranges from $13.5 \%$ 
(range2.6\%-22.9\%) depending upon geographic area and center of study and risk factors including frequent blood transfusion. ${ }^{8}$ In addition to these, they have to undergo recurrent surgeries for access formation and have more frequent extra-corporeal blood exposure.

In Pakistan it is common practice to dialyze such patients on separate dedicated machines with separate area and separate staff yet HCV prevalence of $16.4 \%-61.8 \%$ has been reported from Pakistan. ${ }^{9-15}$ Most of the studies and reviews do not agree with these recommendations, however, in unison recommend universal precautions to control infections. ${ }^{6.8}$ Continuous education of dialysis staff for universal infection prevention strategies including hand washing techniques and needle handling with proper disinfection of machines are the only way to curtail the spread of the disease. This study was undertaken to highlight the high seroconversion rate among incident hemodialysis patients at our center.

\section{Materials and Methods:}

A cross sectional study was conducted at Dialysis center of DHQ hospital, Sheikhupura, Punjab, Pakistan in January 2018. All the patients who initiated hemodialysis with HCV negative status and remained on hemodialysis for more than three months were included in the study. A total of 153 patients, from 16 to 75 years old patients were included in our study.

Exclusion Criteria: Patients with Acute kidney injury (AKI), patients with ESKD who came to center for short time period (less than 3 months), Co-infection with HIV or hepatitis B and Patients with age $<15$ or $>75$ were excluded from study.

All patients were on maintenance dialysis, twice per week, each session of four hours. There was no isolation for HCV positive or negative patients. Dedicated machines were reserved for seropositive patients on same floor, and the area was separated by a small brick wall.

Each dialyzer was being reused three times for dialysis and then discarded. Chemical disinfection of dialyzer with Peracetic acid was done after each hemodialysis session and with proper labeling and stored separately for HCV positive and negative patients. Before next session of hemodialysis cross checking of name for each patient was ensured.

All patients fulfilling the study criteria were enrolled in the study. Demographic data of the patient's (age, gender, occupation and marital state) was collected by direct interview. Viral status, duration on HD, history of blood transfusion(s), attending more than one HD center and type of vascular access for HD (arterio-venous fistula, double lumen catheter, permanent catheter) number of blood transfusions per month was taken from record and noted in preformed Performa. Blood samples were collected pre-dialysis and sent to laboratory for ELISA.

\section{Statistical analysis:}

Data were stored and analyzed using SPSS-IBM version 23.0, count and percentages were reported for qualitative variables like age group, gender, education, employment etc, mean and standard deviation was given for quantitative biochemical parameters, Pearson chi square test was done to see the association of viral infection with baseline and clinical parameters, independent sample t-test was used to compare the mean of biochemical parameters , binary logistic regression was done to estimate the odds with $95 \%$ confidence interval for HCV positive, p-values less than 0.05 were considered significant.

\section{Results:}

Total 153 patients were enrolled in this study. Baseline characteristics are presented in Table 1. Majority 104(68.0\%) were aged above 40 years and 86 (56.2\%) were male. Most (79.0\%) were un-employed and were living in rural areas of district Sheikhupura. Major cause of ESKD were diabetes mellitus [(DM) 47.0\%], hypertension [(HTN) 41.0\%], Table 1. Most of the patients (88.2\%) initiated dialysis with double lumen catheter. Almost all patients (99\%) were being dialyzed twice weekly. Number of dialysis and history of blood transfusion is also shown in Table 1. All patients were receiving erythropoietin 4000 IU twice weekly. Out of the 153 surveyed patients, 93 were negative for $\mathrm{HCV}$ and 60 had seroconverted to $\mathrm{HCV}$ at the time of the study; the point prevalence of $\mathrm{HCV}$ infection was $39.22 \%$. Chi square analysis revealed blood transfusion and number of dialysis as significant factor for seroconversion, Table 2.

\section{Discussion:}

The current study shows a high seroconversion among incident dialysis patients at our center similar to others reported locally and internationally. ${ }^{8,13-15}$ In the recent literature reviewed over the last decade from Pakistan, HCV status was found to be positive among $16.4 \%$ to as high as $61.8 \%$ of hemodialysis patients surveyed. This is alarming since free dialysis facilities are available at governmental levels in Pakistan with many times unsupervised units run by technicians and non-nephrologists outside the main cities. It is further of concern for increasing health care cost on the budget for government as well as for self-paying patients since HCV is associated with increased risk of morbidity and mortality including cirrhosis and hepatocellular carcinoma. (Fabrizi and Messa, 2015). ${ }^{16}$ The death risk may increase 
to 1.57 times in this population. The HCV prevalence $(39.21 \%)$ in our population is too high as compared to other countries like neighboring India $(7.44 \%)$ and U.K $(1.2 \%)^{17}$

Table I: Baseline and clinical Characteristics of 153 maintenance hemodialysis patients.

\begin{tabular}{|c|c|c|c|}
\hline \multicolumn{2}{|c|}{ Characteristics } & \multirow{2}{*}{$\begin{array}{c}\text { Number (\%) } \\
49(32.0 \%)\end{array}$} & \multirow{3}{*}{$\begin{array}{r}\text { p-value } \\
0.48\end{array}$} \\
\hline \multirow{2}{*}{ Age group } & $\leq 40$ Years & & \\
\hline & $>40$ Years & $104(68.0 \%)$ & \\
\hline \multirow{2}{*}{ Gender } & Male & $86(56.2 \%)$ & \multirow{2}{*}{0.35} \\
\hline & Female & $67(43.8 \%)$ & \\
\hline \multirow{2}{*}{ Education } & Literate & $90(58.80 \%)$ & \multirow{2}{*}{0.36} \\
\hline & Illiterate & $63(41.2 \%)$ & \\
\hline \multirow{2}{*}{$\begin{array}{l}\text { Employment } \\
\text { status }\end{array}$} & Employed & $32(20.9 \%)$ & \multirow{2}{*}{0.72} \\
\hline & Unemployed & $121(79.0 \%)$ & \\
\hline \multirow{2}{*}{ Address } & Urban & $75(49.0 \%)$ & \multirow{2}{*}{0.40} \\
\hline & Rural & $78(51.0 \%)$ & \\
\hline \multirow{6}{*}{$\begin{array}{l}\text { Cause of } \\
\text { ESKD }\end{array}$} & DM & $72(47.0 \%)$ & \multirow{6}{*}{0.76} \\
\hline & HTN & $63(41.0 \%)$ & \\
\hline & Stone disease & $5(3.2 \%)$ & \\
\hline & chronic GN & $5(3.3 \%)$ & \\
\hline & cystic disease & $5(3.3 \%)$ & \\
\hline & Other & $3(2.0 \%)$ & \\
\hline \multirow{2}{*}{$\begin{array}{l}\text { Dialysis } \\
\text { Access at } \\
\text { Initiation }\end{array}$} & AVF & $18(11.8 \%)$ & \multirow{2}{*}{$<0.01^{*}$} \\
\hline & Double lumen catheter & $135(88.2 \%)$ & \\
\hline \multirow{3}{*}{$\begin{array}{l}\text { Number of } \\
\text { dialysis }\end{array}$} & $>25<50$ & $29(18.95 \%)$ & \multirow{3}{*}{$0.006^{*}$} \\
\hline & $51-100$ & $44(28.75 \%)$ & \\
\hline & $>100$ & $80(52.28 \%)$ & \\
\hline \multirow{2}{*}{$\begin{array}{l}\text { Need for } \\
\text { transfusion }\end{array}$} & Yes & $112(73.2 \%)$ & \multirow[t]{2}{*}{0.156} \\
\hline & No & $41(26.8 \%)$ & \\
\hline \multirow{3}{*}{$\begin{array}{l}\text { Blood } \\
\text { transfusion } \\
\text { required }\end{array}$} & $<2$ times per month & $98(64.0 \%)$ & \multirow{3}{*}{0.075} \\
\hline & 2-4 times per month & $40(26.1 \%)$ & \\
\hline & more than 4 times per month & $15(9.8 \%)$ & \\
\hline
\end{tabular}

${ }^{*} \mathrm{p}<0.05$ was considered significant

Risk factors for $\mathrm{HCV}$ infection in dialysis are considered to be multiple. ${ }^{18}$ Blood transfusion, chronic hemodialysis, surgical procedures, multiple needle pricks, organ transplantation, occupational exposure among health workers and unprotected sexual contact and socioeconomic status are important risk factors. ${ }^{12,19,20}$

In our study and other recent local studies, most of the patients are from younger age group [40 years, $n=104(68 \%)$ ] which is quite younger than ESRD patients in developed countries 62.8 years. ${ }^{10,12,14,21}$ This is a very sad fact that younger patients are getting both ESRD and HCV infection at relatively younger age. Since males make up majority percentage of dialysis patients among our dialysis units, similarly the prevalence of HCV was also higher among them.

Major causes of ESRD were Diabetes mellitus [72(47\%)] and hypertension [63(41\%)] same as in other parts of world. ${ }^{21}$ Blood transfusion is considered as one of the major risk factor for transmission of HCV viral infection as shown in 480 hemodialysis patients by Ali et.al. ${ }^{13}$ In our study we were however unable to find any significant association of blood transfusion and HCV infection.

Intervention for arteriovenous access is important risk for HCV infection. In our center majority of the patients started dialysis via temporary dialysis catheter as usual in a developing country like Pakistan and reported by Sabir et.al. ${ }^{22}$ Most of the HCV positive patients were also from this group suggesting relative risk of $\mathrm{HCV}$ infection with interventions compared to already placed arteriovenous fistula at the initiation of dialysis. 
All HCV positive patients were being dialyzed on same floor in a restricted area on dedicated machines with dedicated staff. Although HCV positive patients are being dialyzed in a separate designated area in most of the centers in Pakistan, nevertheless, physical separation may be a hanging curtain or just open area with a short distance from the negative side and in our center a low height brick wall. This cannot be considered as true separation of positive patients and frequent movement of staff and patients and attendants is observed in the unit. Time and again the controversy has appeared whether HCV patients should be dialyzed in a separate area, internationally still universal precaustions is advised with no separation of $\mathrm{HCV}$ positive patietns.8

Table-2: HCV status of 153 maintenance hemodialysis and significance of factors on seroconversion.

\begin{tabular}{|c|c|c|c|c|}
\hline \multirow[b]{2}{*}{$\begin{array}{l}\text { Characteristics } \\
\text { Of patients }\end{array}$} & \multirow[b]{2}{*}{$\begin{array}{l}\text { Group of } \\
\text { patients }\end{array}$} & \multicolumn{2}{|c|}{ HCV Status } & \multirow[b]{2}{*}{$P$ value } \\
\hline & & $\begin{array}{l}\text { Positive } \\
\text { n(\%) }\end{array}$ & Negative $n(\%)$ & \\
\hline \multirow[t]{2}{*}{ Age } & $\leq 40$ years & $21(42.85 \%)$ & $28(57.14 \%)$ & \multirow{2}{*}{0.48} \\
\hline & $>40$ years & $39(37.50 \%)$ & $65(62.50 \%)$ & \\
\hline \multirow[t]{2}{*}{ Gender } & Male & 34 (39.53 \%) & 52 (60.46 \%) & \multirow{2}{*}{0.35} \\
\hline & Female & $26(38.80 \%)$ & $41(61.19 \%)$ & \\
\hline \multirow[t]{2}{*}{ Address } & Urban & $29(38.6 \%)$ & $46(61.13 \%)$ & \multirow[b]{2}{*}{0.40} \\
\hline & Rural & 30 (38.46 \%) & $48(61.14 \%)$ & \\
\hline \multirow[t]{2}{*}{ Dialysis started via } & AVF & $7(38.88 \%)$ & $11(61.12 \%)$ & \multirow[b]{2}{*}{$<0.01^{*}$} \\
\hline & Catheter & 52 (38.51 \%) & $83(61.48 \%)$ & \\
\hline \multirow[t]{3}{*}{ Number of dialysis } & $>25-50$ & $11(37.93 \%)$ & $18(62.06 \%)$ & \multirow{3}{*}{$<0.01 *$} \\
\hline & $51-100$ & $19(37.25 \%)$ & $32(62.74 \%)$ & \\
\hline & $>100$ & $31(38.75 \%)$ & $49(61.25 \%)$ & \\
\hline \multirow{2}{*}{$\begin{array}{l}\text { Need for blood } \\
\text { transfusion }\end{array}$} & Yes & $43(38.39 \%)$ & $69(61.60 \%)$ & \multirow[b]{2}{*}{0.156} \\
\hline & No & $16(39.02 \%)$ & $25(60.97 \%)$ & \\
\hline \multirow{3}{*}{$\begin{array}{l}\text { Blood transfusion } \\
\text { required }\end{array}$} & $<2$ times per month & $38(38.77 \%)$ & $60(61.22 \%)$ & \multirow{3}{*}{0.075} \\
\hline & 2-4 times per month & $15(37.55 \%)$ & $25(62.55 \%)$ & \\
\hline & $>4$ times per month & $6(40.0 \%)$ & $9(60.0 \%)$ & \\
\hline
\end{tabular}

$* \mathrm{p}<0.05$ was considered significant using Pearson Chi Square test.

In our center dialyzer was being reused three times before being discarded. Peracetic acid solution was used for sterilization and reprocessed dialyzers were kept in separate areas for $\mathrm{HCV}$ and negative patients before being used on the next session. Although all care was taken still could be one possible source of transmission. This reuse of dialyzer might be the source of infection but in previous studies dialyzer reuse was not considered as significant risk factor HCV infection. It has been suggested that overall rate of transmission is not high among centers reprocessing the dialyzers, nevertheless, separate reprocessing room and storage and; Renalin as sterilant had even less chances of transmission. ${ }^{23}$ Considering our circumstances in implementation of universal precautions for infection control, most of the centers in the country are not in favor of reuse of dialyzer.

\section{Conclusion:}

In conclusion $\mathrm{HCV}$ seroconversion was high among maintenance hemodialysis patients at our center. This emphasizes the importance of wellestablished infection prevention and control practices outlined in guidelines to prevent the significant morbidity and mortality associated with seroconversion of $\mathrm{HCV}$ among maintenance hemodialysis patients with $\mathrm{HCV}$ infection with seroconversion.

\section{Acknowledgements:}

We are grateful to Dr. Baber Amin, Chief Consultant/Research Coordinator DHQ sheikhupura, for his persistent help and encouragement throughout the study.

Conflict of interest: none Declared

\section{References:}

1. KDIGO clinical practice guidelines for the prevention, diagnosis, evaluation, and treatment of hepatitis $\mathrm{C}$ in chronic kidney disease. Kidney Int 2008 Suppl,109;S1-99. 
2. Imran, S., Sheikh, A., Saeed, Z., Khan, S. A., Malik, A. O., Patel, J., Kashif, W. \& Hussain, A.Burden of chronic kidney disease in an urban city of Pakistan, a cross-sectional study. JPakMed Assoc 2015;65,366-9.

3. Jessani S, Bux R, Jafar T H. Prevalence, determinants, and management of chronic kidney disease in Karachi, Pakistan - a community based cross-sectional study. BMC Nephrology 2014:15, 90.

4. Archibald LK, Jarvis WR. Health care-associated infection outbreak investigations by the Centers for Disease Control and Prevention, $1946-$ 2005. Am J Epidemiol 2011;174, S47-64.

5. Allegranzi B, Bagheri Nejad S, Combescure C, Graafmans W, Attar H, Donaldson L, Pittet D. Burden of endemic health-care-associated infection in developing countries: systematic review and meta-analysis. Lancet 2011;377, 228-

6. Thompson ND, Novak RT, Datta D, Cotter S, Arduino MJ, Patel PR et.al. Hepatitis C virus transmission in hemodialysis units: importance of infection control practices and aseptic technique. Infect Control Hosp Epidemiol 2009;30:900-3.

7. Umer M, Iqbal M. Hepatitis C virus prevalence and genotype distribution in Pakistan: Comprehensive review of recent data. World J Gastroenterol 2016;22:1684-700..

8. Nguyen DB, Bixler D, Patel PR. Transmission of hepatitis C virus in the dialysis setting and strategies for its prevention. Semin Dial. 2019 Mar; 32(2): $127-134$.

9. Imtiaz M, Elahi I, Anees M. Prevalence of Malnutrition in Hemodialysis Patients: A Single Center Study. Pak J Kidney Dis 2019;(5):89-96

10. Imtiaz M, Anees M, Gul S. Epidemiological profile of patients with end stage renal disease on maintenance hemodialysis in tertiary referral hospitals. Pak J Kidney Dis 2019;(2):30-34

11. Hussain Y, Shahzad A, Azam S, Munawar N. Hepatitis-C and it's seroconversion in end stage kidney disease patients on maintenance hemodialysis and factors affecting it Pak J Med Sci. 2019;35(1):66-70.

12. Irshad AN, Rafique Z, Rehman HS, Asrar A. Socioeconomic Status of Maintenance Hemodialysis Patients from a Tertiary Care Hospital in Lahore. Pak J Kidney Dis 2019;(10):180-186

13. Ali N, Hussain W, Hayat A, Shah T, Wen R, Zeb I, Abdul Malik A, Ramzan R, Rehman MU, Khan I. Prevalence and risk factors of hepatitis B and C viruses mong haemodialysis patients: a multicentric study Eur J Gastroenterol Hepatol. 2019;31(1):29-33.

14. Shahbaz M. Data from a large hemodialysis center form an industrial city: Demographics, etiology and hepatitis status. Pak J Kidney Dis 2019;(10):173-179

15. Amjad U, Ahmad SQ, Mir S, Ayub M.Association of anti-HCV sero-prevalence with blood transfusion and practice of haemodialysis from multiple centres in patients on maintenance haemodialysis. Pak J Med Sci. 2020;36(2):286-289.

16. Fabrizi, F. \& Messa, P. Transmission of Hepatitis C Virus in Dialysis Units: A Systematic Review of Reports on Outbreaks. Int J Artif Organs $2015 ; 38,471-480$

17. Petruzziello, A., Marigliano, S., Loquercio, G., Cozzolino, A. \& Cacciapuoti, C. Global epidemiology of hepatitis C virus infection: An update of the distribution and circulation of hepatitis C virus genotypes. World J Gastroenterol 2016;22:7824-40.

18. Somi MH., Etemadi J., Ghojazadeh, M, Farhangm S, Faramarzim M., Foroutan S, Soleimanpour M. Risk factors of HCV seroconversion in hemodialysis patients in tabriz, iran. Hepat Mon 2014;14: e17417.

19. Prati, D.Transmission of hepatitis C virus by blood transfusions and other medical procedures: a global review.J Hepatol 2006;45:607-16.

20. Fissell RB, Bragg-Gresham JL, Woods JD, Jadoul M, Gillespie B, Hedderwick S A et.al. Patterns of hepatitis C prevalence and seroconversion in hemodialysis units from three continents: the DOPPS. Kidney Int 2004:65: 2335-42.

21. USRSD data System ; https://www.usrds.org/reference.aspx. Last accessed on March 12, 2020

22. Sabir O, Riaz MM. Rafique K, Anjum N, Abbas G, Akram M. Fistula First: Are we there yet? A multicenter study. Pak J Kidney Dis 2017(1);3:21-26.

23. J P dos Santos, A Loureiro, M Cendoroglo Neto, B J Pereira. Impact of Dialysis Room and Reuse Strategies on the Incidence of Hepatitis C Virus Infection in Haemodialysis Units Nephrol Dial Transplant.1996(11); 10:2017-22. 